\title{
Universal COVID-19 Vaccine Targeting SARS-CoV-2 Envelope Protein
}

\author{
Chung-Min Tsai', \\ ${ }^{1}$ Graduate Institute of Medical Sciences, Taipei Medical University, Taiwan \\ ${ }^{2}$ MacKay Children's Hospital, Taiwan \\ Email: d119102012@tmu.edu.tw
}

How to cite this paper: Tsai, C.-M. (2021) Universal COVID-19 Vaccine Targeting SARS-CoV-2 Envelope Protein. World Journal of Vaccines, 11, 19-27. https://doi.org/10.4236/wjv.2021.113003

Received: March 23, 2021

Accepted: July 5, 2021

Published: July 8, 2021

Copyright $\odot 2021$ by author(s) and Scientific Research Publishing Inc. This work is licensed under the Creative Commons Attribution International License (CC BY 4.0).

http://creativecommons.org/licenses/by/4.0/

\begin{abstract}
The coronavirus disease 2019 (COVID-19) pandemic, caused by severe acute respiratory syndrome coronavirus 2 (SARS-CoV-2), had caused over 382 million cases and over 2.7 million deaths globally as of 23 March 2021. By that date, at least 10 SARS-CoV-2 variants had emerged. The transmissibility and lethality of the variants are higher than those of the Wuhan reference strain. Therefore, a universal vaccine for the reference strain and all variants (present and future) is indispensable. The coronavirus envelope (E) protein is an integral membrane protein crucial to the viral lifecycle and the pathogenesis of coronaviruses. The SARS-CoV-2 E protein has a postsynaptic density protein 95/Drosophila disc large tumor suppressor/zonula occludens-1 (PDZ) binding motif (PBM), and its interaction with PDZ-domain-2 of the human tight junction protein may interrupt the integrity of lung epithelium. Furthermore, the SARS-CoV-2 E protein itself is a homopentameric cation channel viroporin, which may be involved in viral release. This protein is thus a potential target for the development of a universal COVID-19 vaccine, because of its highly conserved amino acid sequence. The variant mutations occur mainly in the spike protein, and conservation of $\mathrm{E}$ protein remained in most Variants of Concern (VOC). Only one of the extant VOC have mutations in the $\mathrm{E}$ protein that $\mathrm{P} 71 \mathrm{~L}$ mutation occurs in the South African variant 501Y.V2 (B.1.351). If a vaccine is designed to target $\mathrm{E}$ protein, two scenarios are possible: 1) SARS-CoV-2 maintains a highly conserved E protein amino acid sequence, rendering the virus consistently or permanently susceptible to the vaccine; or 2) the E protein mutates and new variants evolve accordingly. In scenario 2, the tertiary structure and function of the $\mathrm{E}$ protein homopentameric cation channel viroporin, $\mathrm{PBM}$, or other aspects affecting pathogenicity would be attenuated. Either scenario would thus ameliorate the pandemic. I therefore propose that a vaccine targeting the SARS-CoV-2 E protein would be effective against the Wuhan reference strain and all current and fu-
\end{abstract}


ture SARS-CoV-2 variants. Efforts to create E protein-based vaccines are on-

going. Further research and clinical trials are needed to realize this universal

COVID-19 vaccine.

\section{Keywords}

COVID-19, SARS-CoV-2, Envelope Protein, Universal COVID-19 Vaccine

\section{Introduction}

The coronavirus disease 2019 (COVID-19) pandemic, caused by severe acute respiratory syndrome coronavirus 2 (SARS-CoV-2), has already led to more than 382 million cases and more than 2.7 million deaths globally as of 23 March 2021 [1]. Here, I have presented the following hypothesis regarding a universal COVID-19 vaccine targeting the SARS-CoV-2 E protein: "a vaccine targeting the SARS-CoV-2 E protein would be effective against the SARS-CoV-2 Wuhan reference strain and all current and future SARS-CoV-2 variants. The SARS-CoV-2 which causes COVID-19 cases in Wuhan, China [2] is designated as the "Wuhan reference strain", while the SARS-CoV-2 strains with mutations are referred to as variants. Thus far, several variants have emerged, including mink Cluster 5, lineage B.1.525, lineage P.3, the UK variants (B.1.1.7, variant of concern [VOC] 202012/01, and VOC 202102/02), Indian variant (B.1.617), Nigerian variant (B.1.1.207), South African variant (B.1.351), California variants (B.1.429 and B.1.427), Brazil variants (lineages P.1 and P.2), and le variant Breton. The B.1.1.7 variant has increased the lethality of the disease from 2.5/1000 to 4.1/1000 [3].

Currently available vaccines are based on spike protein. The Pfizer/BioNTech and Oxford-AstraZeneca vaccines provided protection against the UK variant of concern (B.1.1.7) [4]. However, whether the currently available spike (S) protein-based COVID-19 vaccines from Pfizer/BioNTech, Moderna, Oxford-AstraZeneca, and Johnson \& Johnson have a protective effect against the Indian variant (B.1.617) is still uncertain. Even if these vaccines are effective against B.1.617, there might be still new emergence of SARS-CoV-2 variants, thus a universal vaccine for all variants of SARS-CoV-2 is urgently needed. Firstly, immune escape variants may still emerge [5] under the pressure of population-level vaccination with $S$ protein-targeting vaccines. Secondly, the advantage of a universal COVID-19 vaccine is that there would be no need for modifications to target new variants. If the current $S$ protein-based vaccines are found to be ineffective against any of the variants, a universal COVID-19 vaccine would indeed be indispensable.

The development of a universal COVID-19 vaccine would rely on an understanding of the origin of SARS-CoV-2 and its pathogenic mechanisms so that the appropriate corresponding strategies can be applied to vaccine design. Although the origin of SARS-CoV-2 is still under investigation, two bat SARS-like (SL) coronaviruses, bat-SL-CoVZC45 and bat-SL-CoVZXC21, should be taken into account. One of the earliest studies on COVID-19 after the outbreak in 
Wuhan [6], which was received by the journal Emerging Microbes \& Infections on 16 January 2020 and published online on 28 January 2020, revealed that SARS-CoV-2 is most closely related to these two bat SARS-like coronaviruses. Indeed, the genome of human 2019-nCoV HKU-SZ-005b (accession: MN975262) had 89\% nucleotide identity with bat-SL-CoVZXC21 [7] (accession: MG772934; http://www.ncbi.nlm.nih.gov/nuccore/1369125429,

https://www.ncbi.nlm.nih.gov/nuccore/MG772934). The complete genomes of bat-SL-CoVZC45 [8] (accession: MG772933

http://www.ncbi.nlm.nih.gov/nuccore/1369125417,

https://www.ncbi.nlm.nih.gov/nuccore/MG772933.1) and bat-SL-CoVZXC21 were isolated from the mitochondrial cytochrome $b$ gene in the muscle tissues of Rhinolophus pusillus bats in Zhoushan City, Zhejiang province, China, between 2015 and 2017, and reported by Hu et al. in 2018 [9]. Bat-SL-CoVZC45 can infect rat lungs, where it causes partial fusion of alveolar cavities and mild emphysema [9]. The complete genome of bat-SL-CoVZC45 and bat-SL-CoVZXC21 were submitted by Dan $\mathrm{Hu}$, Institute of Military Medicine Nanjing Command, Nanjing, Institute of Military Medicine Nanjing Command, Nanjing, China on 5 January 2018 [7] [8].

Among the amino acid sequences of SARS-CoV-2, the amino acid sequence of the structural protein envelope (E) protein

(MYSFVSEETGTLIVNSVLLFLAFVVFLLVTLAILTALRLCAYCCNIVNVSLVK PSFYVYSRVKNLNSSRVPDLLV) had the highest similarity to the bat isolates: it was $100 \%$ identical to that of the E protein from both bat-SL-CoVZXC21 and bat-SL-CoVZC45 [6] [10]. Notably, three nucleotides of the SARS-CoV-2 E protein gene (C26313, T26331, C26464) were different from those of bat-SLCoVZC45 (T26218, C26236, T23369) and bat-SL-CoVZXC21 (T26149, C26167, $\mathrm{T} 26300$ ), according to the BLAST results. The amino acid sequence of the $\mathrm{E}$ protein of the bat coronavirus RaTG13 is also identical to that of SARS-CoV-2. RaTG13 is the closest relative to SARS-CoV-2, with a genome that is generally acknowledged to be $96 \%$ identical to it, and was claimed to have been discovered in Yunnan, China in 2013 [11], a narrative that is currently widely accepted by the scientific community. However, the nature of the development of RaTG13 is questionable, since the study on it and its genome was submitted only after the first emergence of COVID-19. That study, which was authored by Chou et al. [11], Prof. Zhengli Shi's research group, was received by the journal Nature on 20 January 2020 and published online on 3 February, and the genome (accession: MN996532; https://www.ncbi.nlm.nih.gov/nuccore/1916859392) was submitted by Zhu et al. on 27 January 2020. A challenge to the natural existence of RaTG13 has been summarized by Yan et al. [10], and further solid evidence against its natural existence was later published by the same authors [12].

The coronavirus E protein is a small integral 75 amino acid membrane protein involved in crucial aspects of the viral lifecycle, including assembly, budding, envelope formation, and pathogenesis [13]. The E protein of SARS-CoV is indispensable for viral replication [14]. Furthermore, the SARS-CoV E protein has 
a binding motif at its $\mathrm{C}$-terminal end called postsynaptic density protein 95/Drosophila disc large tumor suppressor/zonula occludens-1 protein (zo-1) (PDZ)-binding motif (PBM), which can disrupt the integrity of lung epithelium [15]. The SARS-CoV-2 E protein also has a PBM at its C-terminal end (DLLV:72-75), and it interacts with PDZ-domain-2 of human ZO-1 [16]. The coronavirus $\mathrm{E}$ protein also forms viroporins that may mediate viral release [13] [17]. Tomar and Arkin [18] revealed that the SARS-CoV-2 E protein may be an ion channel viroporin. Further, Saurabh and colleagues [19] described the Born-Poisson-Nernst-Planck-Lennard-Jones model illustrating the flow of $\mathrm{Na}+$ and $\mathrm{Cl}-$ through ion channel viroporins formed by pentameric SARS-CoV-2 E proteins. Mandala and colleagues [20] investigated the $2.1 \AA$ structure of the E protein's transmembrane (ETM) domain via solid-state nuclear magnetic resonance spectroscopy, and they found that the ETM forms a homopentameric cation with a five-helix bundle surrounding a narrow pore. Finally, Cabrera-Garcia and colleagues [21] demonstrated that the SARS-CoV-2 E protein increases the intra-Golgi $\mathrm{pH}$ and regulates the homopentameric cation channel via $\mathrm{pH}$.

We can infer that the tertiary structure of the $\mathrm{E}$ protein is the same in SARS-CoV-2 as in ZC45 and ZXC21, since the amino acid sequences are identical. Further, we can infer that all strains of SARS-CoV-2 that have developed since the outbreak have almost the same tertiary structure, since $98.8 \%$ of SARS-CoV-2 strains are highly conserved, with an extremely low mutation rate: $1.2 \%$ of SARS-CoV-2 strains had gene mutations (synonymous and nonsynonymous) from the Wuhan reference strain [22]. High levels of amino acid variation in the PBM (D72Y, D72G, D72H, D72N, D72V, and D72A; L73F, L73V; L74P, L74V; V75L, V75F) have been observed [22], and these may alter the binding of the SARS-CoV-2 E protein to ZO-1 and/or protein associated with LIN7 1 (PALS1) [22]. Except for the V25A mutation in the transmembrane domain [22], most of the mutations do not affect the tertiary structure with respect to the homopentameric cation channel viroporin. If SARS-CoV-2 accrues further mutations in areas that are currently not mutated, the tertiary structure will be altered, which would eventually lead to the malfunction of the E protein viroporin.

The SARS-CoV-2 E protein has a highly conserved amino acid sequence [21]. Importantly, the $\mathrm{E}$ protein of the B.1.1.7 variant was not mutated relative to the Wuhan reference strain (Table 1). The multiple mutations in VOC 201212/01 (B.1.1.7) are located within the S, ORF1ab, Orf8, and nucleocapsid $(\mathrm{N})$ proteins [23], and the E protein is not mutated at all. Most of the multiple mutations of South African variant 501Y.V2 (B.1.351) are located in the spike protein [24]. Most Variants of Concern including Indian variant (B1.617) remained the identical amino acid sequence of $\mathrm{E}$ protein as that of the Wuhan reference strain. Only a P71L mutation located in the E protein of the South African variant 501Y.V2 (B.1.351) was noted among all Variants of Concern at present (Table 1). Singh et al. [25] had reported the P71L mutation in the E protein of 501Y.V2. 
Table 1. The amino acid sequence of the SARS-CoV-2 envelope protein of Variants of Concern.

\begin{tabular}{|c|c|c|}
\hline \multirow{2}{*}{ Lineage (Fist detection) } & \multicolumn{2}{|l|}{ Envelope protein } \\
\hline & Amino acid sequence $^{\mathrm{a}}$ & Accession \\
\hline B.1.1.7 (UK) & $\begin{array}{l}\text { MYSFVSEETGTLIVNSVLLFLAFVVFLLVTLAILTALRLC } \\
\text { AYCCNIVNVSLVKPSFYVYSRVKNLNSSRVPDLLV }\end{array}$ & QVI17691 \\
\hline B.1.617.1 (India) & $\begin{array}{l}\text { MYSFVSEETGTLIVNSVLLFLAFVVFLLVTLAILTALRLC } \\
\text { AYCCNIVNVSLVKPSFYVYSRVKNLNSSRVPDLLV }\end{array}$ & QTP09030 \\
\hline B.1.617.2 (India) & $\begin{array}{l}\text { MYSFVSEETGTLIVNSVLLFLAFVVFLLVTLAILTALRLC } \\
\text { AYCCNIVNVSLVKPSFYVYSRVKNLNSSRVPDLLV }\end{array}$ & QTW58948 \\
\hline $\begin{array}{l}\text { B.1.351/501Y.V2 } \\
\text { (South Africa) }\end{array}$ & $\begin{array}{l}\text { MYSFVSEETGTLIVNSVLLFLAFVVFLLVTLAILTALRLC } \\
\text { AYCCNIVNVSLVKPSFYVYSRVKNLNSSRVLDLLV }\end{array}$ & QVI03432 \\
\hline B.1.427 (USA) & $\begin{array}{l}\text { MYSFVSEETGTLIVNSVLLFLAFVVFLLVTLAILTALRLC } \\
\text { AYCCNIVNVSLVKPSFYVYSRVKNLNSSRVPFLLV }\end{array}$ & QSF02699 \\
\hline B.1.429 (USA) & $\begin{array}{l}\text { MYSFVSEETGTLIVNSVLLFLAFVVFLLVTLAILTALRLCA } \\
\text { YCCNIVNVSLVKPSFYVYSRVKNLNSSRVPDLLV }\end{array}$ & QVI45778 \\
\hline P.1 (Japan and Brazil) & $\begin{array}{l}\text { MYSFVSEETGTLIVNSVLLFLAFVVFLLVTLAILTALRLC } \\
\text { AYCCNIVNVSLVKPSFYVYSRVKNLNSSRVPDLLV }\end{array}$ & QVJ13923 \\
\hline Wuhan reference strain & $\begin{array}{l}\text { MYSFVSEETGTLIVNSVLLFLAFVVFLLVTLAILTALRLCA } \\
\text { YCCNIVNVSLVKPSFYVYSRVKNLNSSRVPDLLV }\end{array}$ & NC_045512 \\
\hline
\end{tabular}

a. The randomization method of the sample selection was by selecting the latest released protein sequence with envelope protein on the SARS-CoV-2 Data Hub, NCBI Virus

(https://www.ncbi.nlm.nih.gov/labs/virus/vssi/\#/virus?SeqType_s=Protein\&VirusLineage_ss=SARS-CoV-2, \%20taxid:2697049), of each lineage by the date of 19 May 2021 (The date of manuscript revision after acceptance). The amino acid sequences were obtained from the GenBank Protein (https://www.ncbi.nlm.nih.gov/protein) according to the corresponding Accession of the complete or partial genome. b. The amino acid sequences were identical to the that of the Wuhan reference strain.

These facts suggest a strategy for developing a universal vaccine against SARS-CoV-2 that would be effective against all variants, current and future: a vaccine based on the E protein. There are two possible scenarios that may occur in response to such a vaccine:

1) If the highly conserved $\mathrm{E}$ protein amino acid sequence is maintained, SARS-CoV-2 (including all variants) would be consistently or permanently susceptible to the vaccine.

2) If the E protein accrues more mutations than it has previously and accordingly evolved into further variants, the tertiary structure and function of the $\mathrm{E}$ protein homopentameric cation channel viroporin and PBM would be attenuated. This would necessarily attenuate the pathogenicity of SARS-CoV-2, which is governed by replication, assembly, budding, and envelope formation.

Both of these scenarios are unfavorable for the further spread of SARS-CoV-2 and may thus attenuate the COVID-19 pandemic.

\section{The Hypothesis}

A vaccine targeting the SARS-CoV-2 E protein would be effective against the SARS-CoV-2 Wuhan reference strain and all current and future SARS-CoV-2 variants. 


\section{Discussion}

\subsection{Evaluation of the Hypothesis}

Bhattacharya et al. [26] first systemically proposed SARS-CoV-2 E protein as a suitable target for vaccine development, and Bhattacharya et al. [26]. Recently, an in silico approach to developing an E protein-based COVID-19 vaccine using a chimeric peptide found that the vaccine had a high affinity to major histocompatibility complex (MHC) molecules [27]. There is also an ongoing research into another peptide-based vaccine, using predicted epitopes in the envelope protein [28]. Furthermore, multiepitope-based peptide vaccine against SARS-CoV-2 E protein were designed based on T-cell epitope-based peptide immunization, in which the world population coverage of MHC class II could be up to $99.99 \%$ [29].

\subsection{Consequences of the Hypothesis and Discussion}

This hypothetic study focuses on the concept of a universal vaccine targeting the E protein. It will be up to future experimental approaches and clinical trials to accept or reject my hypothesis. If the hypothesis is accepted, this study may contribute to the development of a universal COVID-19 vaccine. Once a universal COVID-19 vaccine is established, there would be no need for modifications to it when new variants emerge, and such a vaccine may help to end the COVID-19 pandemic.

\subsection{The Bridge between the Current $S$ Protein-Based Vaccines and the Future E Protein-Based Universal Vaccine}

If an $\mathrm{E}$ protein-based universal vaccine becomes available in the future, people who have already been vaccinated with $S$ protein-based vaccines will be able to receive the E protein-based vaccine without immune system conflicts. The current $S$ protein-based vaccines enable the immune system to recognize the $S$ protein of SARS-CoV-2 and trigger innate and adaptive responses [30]. The E protein-based universal vaccine would enable the immune system to independently recognize the $\mathrm{E}$ protein, and should provide coverage against all variants. It would therefore be safe to receive an E protein-based universal vaccine after receiving an $\mathrm{S}$ protein-based vaccine.

\subsection{From Hypothesis to Arms}

The SARS-CoV-2 E protein had been identified as a potential target for vaccine development even before the variants started to emerge [31]. Variants have now been circulating for at least four months, and we know that the E protein of all variants has remained unmutated. This fact, together with the functional role of the $\mathrm{E}$ protein in the pathogenicity of the virus, has suggested my hypothesis. If it is shown to be correct, in vitro studies, in vivo studies, and clinical trials should be commenced as early as possible, building on the current experiences of COVID-19 vaccine development. 


\section{Conclusion}

COVID-19 variants emerge and threaten lives globally, yet the current S protein-based vaccines may be less effective against variants than they are against the Wuhan reference strain, because of mutations in the spike protein. Here, I have presented the following hypothesis regarding a universal COVID-19 vaccine targeting the SARS-CoV-2 E protein: "a vaccine targeting the SARS-CoV-2 E protein would be effective against the SARS-CoV-2 Wuhan reference strain and all current and future SARS-CoV-2 variants." The main concept of the hypothesis is based on the highly conserved $\mathrm{E}$ protein amino acid sequence and the fact that this protein is unmutated in the variants, as well as on the pathogenic role of the E protein. If this hypothesis is accepted, such a universal COVID-19 vaccine targeting the E protein may help to end the COVID-19 pandemic.

\section{Acknowledgements}

I would like to thank Uni-edit (https://www.uni-edit.net/) for editing and proofreading this manuscript.

\section{Conflicts of Interest}

The author discloses no financial or personal relationships with other people or organizations that could inappropriately influence or bias this work.

\section{References}

[1] Johns Hopkins University (2021) COVID-19 Dashboard. Center for Systems Science and Engineering (CSSE) at Johns Hopkins University (JHU), Baltimore. https://coronavirus.jhu.edu/map.html

[2] Huang, C., Wang, Y., Li, X., Ren, L., Zhao, J., Hu, Y., et al. (2020) Clinical Features of Patients Infected with 2019 Novel Coronavirus in Wuhan, China. Lancet, 395, 497-506. https://doi.org/10.1016/S0140-6736(20)30183-5

[3] Challen, R., Brooks-Pollock, E., Read, J.M., Dyson, L., Tsaneva-Atanasova, K., et al. (2021) Risk of Mortality in Patients Infected with SARS-CoV-2 Variant of Concern 202012/1: Matched Cohort Study. BMJ, 372, n579.

https://doi.org/10.1136/bmj.n579

[4] Lopez Bernal, J., Andrews, N., Gower, C., Robertson, C., Stowe, J., et al. (2021) Effectiveness of the Pfizer-BioNTech and Oxford-AstraZeneca Vaccines on Covid-19 Related Symptoms, Hospital Admissions, and Mortality in Older Adults in England: Test Negative Case-Control study. BMJ, 373, n1088.

https://doi.org/10.1136/bmj.n1088

[5] Sheridan, C. (2021) Innovators Target Vaccines for Variants and Shortages in Global South. Nature Biotechnology, 39, 393-396. https://doi.org/10.1038/d41587-021-00001-x

[6] Chan, J.F., Kok, K.H., Zhu, Z., Chu, H., To, K.K., et al. (2020) Genomic Characterization of the 2019 Novel Human-Pathogenic Coronavirus Isolated from a Patient with Atypical Pneumonia after Visiting Wuhan. Emerging Microbes \& Infections, 9, 221-236. https://doi.org/10.1080/22221751.2020.1719902

[7] Hu, D. (2018) Bat SARS-Like Coronavirus Isolate Bat-SL-CoVZXC21, Complete 
Genome. GeneBank. https://www.ncbi.nlm.nih.gov/nuccore/MG772934

[8] Hu, D. (2018) Bat SARS-Like Coronavirus Isolate Bat-SL-CoVZC45, Complete Genome. GenBank. https://www.ncbi.nlm.nih.gov/nuccore/MG772933.1

[9] Hu, D., Zhu, C., Ai, L., He, T., Wang, Y., Ye, F., et al. (2018) Genomic Characterization and Infectivity of a Novel SARS-Like Coronavirus in Chinese Bats. Emerging Microbes \& Infections, 7, Article No. 154. https://doi.org/10.1038/s41426-018-0155-5

[10] Yan, L.M., Kang, S., Guan, J. and Hu, S. (2020) Unusual Features of the SARS-CoV-2 Genome Suggesting Sophisticated Laboratory Modification Rather Than Natural Evolution and Delineation of Its Probable Synthetic Route. Zenodo. http://doi.org/10.5281/zenodo.4028830

[11] Zhou, P., Yang, X.L., Wang, X.G., Hu, B., Zhang, L., Zhang, W., et al. (2020) A Pneumonia Outbreak Associated with a New Coronavirus of Probable Bat Origin. Nature, 579, 270-273. https://doi.org/10.1038/s41586-020-2012-7

[12] Yan, L.M., Kang, S., Guan, J. and Hu, S. (2020) SARS-CoV-2 Is an Unrestricted Bioweapon: A Truth Revealed through Uncovering a Large-Scale, Organized Scientific Fraud. Zenodo.

[13] Schoeman, D. and Fielding, B.C. (2019) Coronavirus Envelope Protein: Current Knowledge. Virology Journal, 16, Article No. 69.

https://doi.org/10.1186/s12985-019-1182-0

[14] DeDiego, M.L., Alvarez, E., Almazán, F., Rejas, M.T., Lamirande, E., Roberts, A., et al. (2007) A Severe Acute Respiratory Syndrome Coronavirus That Lacks the E Gene Is Attenuated in Vitro and in Vivo. Journal of Virology, 81, 1701-1713. https://doi.org/10.1128/JVI.01467-06

[15] Teoh, K.T., Siu, Y.L., Chan, W.L., Schluter, M.A., Liu, C.J., et al. (2010) The SARS Coronavirus E Protein Interacts with PALS1 and Alters Tight Junction Formation and Epithelial Morphogenesis. Molecular Biology of the Cell, 21, 3838-3552. https://doi.org/10.1091/mbc.e10-04-0338

[16] Shepley-McTaggart, A., Sagum, C.A., Oliva, I., Rybakovsky, E., DiGuilio, K., et al. (2020) SARS-CoV-2 Envelope (E) Protein Interacts with PDZ-Domain-2 of Host Tight Junction Protein ZO1. bioRxiv. https://doi.org/10.1101/2020.12.22.422708

[17] Westerbeck, J.W. and C.E. Machamer (2019) The Infectious Bronchitis Coronavirus Envelope Protein Alters Golgi pH To Protect the Spike Protein and Promote the Release of Infectious Virus. Journal of Virology, 93, e00015-19. https://doi.org/10.1128/JVI.00015-19

[18] Tomar, P.P.S. and I.T. Arkin (2020) SARS-CoV-2 E Protein Is a Potential Ion Channel That Can Be Inhibited by Gliclazide and Memantine. Biochemical and Biophysical Research Communications, 530, 10-14. https://doi.org/10.1016/j.bbrc.2020.05.206

[19] Saurabh, K., Solovchuk, M. and Sheu, T.W. (2020) Investigating Ion Transport Inside the Pentameric Ion Channel Encoded in COVID-19 E Protein. Physical Review E, 102, Article ID: 052408. https://doi.org/10.1103/PhysRevE.102.052408

[20] Mandala, V.S., M.J. McKay, A.A. Shcherbakov, A.J. Dregni, A. Kolocouris, et al. (2020) Structure and Drug Binding of the SARS-CoV-2 Envelope Protein Transmembrane Domain in Lipid Bilayers. Nature Structural \& Molecular Biology, 27, 1202-1208. https://doi.org/10.1038/s41594-020-00536-8

[21] Cabrera-Garcia, D., Bekdash, R., Abbott, G.W., Yazawa, M. and Harrison, N.L. (2021) The Envelope Protein of SARS-CoV-2 Increases Intra-Golgi pH and Forms a Cation Channel That Is Regulated by $\mathrm{pH}$. The Journal of Physiology, 599, 
2851-2868. https://doi.org/10.1113/JP281601

[22] Rahman, M.S., Hoque, M.N., Islam, M.R., Islam, I., Mishu, I.D., Rahaman, M.M., et al. (2020) Mutational Insights into the Envelope Protein of SARS-CoV-2. Gene Reports, 1, Article ID: 2020080665. https://doi.org/10.20944/preprints202008.0665.v1

[23] Rambaut, A., Loman, N., Pybus, O., Barclay, W., Barrett, J., et al. (2021) Preliminary Genomic Characterisation of an Emergent SARS-CoV-2 Lineage in the UK Defined by a Novel Set of Spike Mutations. Virological.

https://virological.org/t/preliminary-genomic-characterisation-of-an-emergent-sars -cov-2-lineage-in-the-uk-defined-by-a-novel-set-of-spike-mutations/563

[24] Africa Centres for Disease Control and Prevention (2020) Alert Notification: New SARS-CoV-2 Variant with Multiple Spike Protein Mutations. Africa Centres for Disease Control and Prevention, Addis Ababa.

https://africacdc.org/download/alert-notification-new-sars-cov-2-variant-with-mult iple-spike-protein-mutations/

[25] Singh, J., Samal, J., Kumar, V., Sharma, J., Agrawal, U., et al. (2021) Structure-Function Analyses of New SARS-CoV-2 Variants B.1.1.7, B.1.351 and B.1.1.28.1: Clinical, Diagnostic, Therapeutic and Public Health Implications. Viruses, 13, Article No. 439. https://doi.org/10.3390/v13030439

[26] Bhattacharya, S., Banerjee, A. and Ray, S. (2021) Development of New Vaccine Target against SARS-CoV2 Using Envelope (E) Protein: An Evolutionary, Molecular Modeling and Docking Based Study. International Journal of Biological Macromolecules, 172, 74-81. https://doi.org/10.1016/j.ijbiomac.2020.12.192

[27] Ghafouri, F., Cohan, R.A., Noorbakhsh, F., Samimi, H. and Haghpanah, V. (2020) An In-Silico Approach to Develop of a Multi-Epitope Vaccine Candidate against SARS-CoV-2 Envelope (E) Protein. Research Square. [Preprint]. https://doi.org/10.21203/rs.3.rs-30374/v1

[28] Jakhar, R. and Gakhar, S.K. (2020) An Immunoinformatics Study to Predict Epitopes in the Envelope Protein of SARS-CoV-2. Canadian Journal of Infectious Diseases and Medical Microbiology, 2020, Article ID: 7079356. https://doi.org/10.1155/2020/7079356

[29] Abdelmageed, M.I., Abdelmoneim, A.H., Mustafa, M.I., Elfadol, N.M., Murshed, N.S., et al. (2020) Design of a Multiepitope-Based Peptide Vaccine against the E Protein of Human COVID-19: An Immunoinformatics Approach. Biomed Res Int, 2020, Article ID: 2683286. https://doi.org/10.1155/2020/2683286

[30] Teijaro, J.R. and Farber, D.L. (2021) COVID-19 Vaccines: Modes of Immune Activation and Future Challenges. Nature Reviews Immunology, 21, 195-197. https://doi.org/10.1038/s41577-021-00526-X

[31] Sarkar, M. and Saha, S. (2020) Structural Insight into the Role of Novel SARS-CoV-2 E Protein: A Potential Target for Vaccine Development and Other Therapeutic Strategies. PLoS ONE, 15, e0237300.

https://doi.org/10.1371/journal.pone. 0237300 